\title{
Does transforaminal lumbar interbody fusion induce lordosis or kyphosis? Radiographic evaluation with a minimum 2-year follow-up
}

\author{
Jinping Liu, MD, ${ }^{1,2}$ Pingguo Duan, MD, ${ }^{1}$ Praveen V. Mummaneni, MD, MBA, ${ }^{1}$ Rong Xie, MD, ${ }^{1}$ \\ Bo Li, MD, ${ }^{1}$ Yinhui Dong, MD, ${ }^{1}$ Sigurd Berven, MD, ${ }^{1}$ and Dean Chou, MD ${ }^{1}$ \\ 1Department of Neurological Surgery, University of California, San Francisco, California; and 2Department of Neurosurgery, \\ Sichuan Academy of Medical Sciences and Sichuan Provincial People's Hospital, School of Medicine, University of Electronic \\ Science and Technology of China, Chengdu, Sichuan, China
}

OBJECTIVE Conflicting reports exist about whether transforaminal lumbar interbody fusion (TLIF) induces lordosis or kyphosis, ranging from decreasing lordosis by $3.71^{\circ}$ to increasing it by $18.8^{\circ}$. In this study, the authors' aim was to identify factors that result in kyphosis or lordosis after TLIF.

METHODS A single-center, retrospective study of open TLIF without osteotomy for spondylolisthesis with a minimum 2-year follow-up was undertaken. Preoperative and postoperative clinical and radiographic parameters and cage specifics were collected. TLIFs were considered to be "lordosing" if postoperative induction of lordosis was $>0^{\circ}$ and "kyphosing" if postoperative induction of lordosis was $\leq 0^{\circ}$.

RESULTS A total of 137 patients with an average follow-up of 52.5 months (range 24-130 months) were included. The overall postoperative disc angle (DA) and segmental lordosis $(S L)$ increased by $1.96^{\circ}$ and $1.88^{\circ}(p=0.003$ and $p=0.038)$, respectively, whereas overall lumbar lordosis remained unchanged $(p=0.133)$. Seventy-nine patients had lordosing TLIFs with a mean SL increase of $5.72^{\circ} \pm 3.97^{\circ}$, and 58 patients had kyphosing TLIFs with a mean decrease of $3.02^{\circ} \pm 2.98^{\circ}$. Multivariate analysis showed that a lower preoperative DA, lower preoperative SL, and anterior cage placement were correlated with the greatest increase in postoperative $S L(p=0.040, p<0.001$, and $p=0.035$, respectively). There was no difference in demographics, cage type or height, or spinopelvic parameters between the groups ( $p$ $>0.05)$. Linear regression showed that the preoperative $D A$ and $S L$ correlated with $S L$ after TLIF $\left(R^{2}=0.198, p<0.001\right.$; and $R^{2}=0.2931, p<0.001$, respectively).

CONCLUSIONS Whether a TLIF induces kyphosis or lordosis depends on the preoperative DA, preoperative SL, and cage position. Less-lordotic segments became more lordotic postoperatively, and highly lordotic segments may lose lordosis after TLIF. Cages placed more anteriorly were associated with more lordosis.

https://thejns.org/doi/abs/10.3171/2020.12.SPINE201665

KEYWORDS transforaminal lumbar interbody fusion; lumbar lordosis; segmental lordosis; disc angle; spondylolisthesis; TLIF

$\mathrm{T}$ RANSFORAMINAL lumbar interbody fusion (TLIF) is a very useful method of distracting the interbody space, alleviating foraminal stenosis, stabilizing the spine, and decompressing the neural elements all through a posterior approach. However, conflicting reports exist about the extent to which TLIF induces lordosis or even induces kyphosis. For instance, Jagannathan et al. ${ }^{1}$ report- ed increases in lumbar lordosis (LL) by $17.3^{\circ}, 27.5^{\circ}$, and $31.0^{\circ}$ with 1-, 2-, and 3-level TLIFs, respectively. However, Hsieh et al. ${ }^{2}$ reported that TLIF decreased segmental lordosis (SL) by $0.1^{\circ}$ and overall LL by $2.1^{\circ}$. Dorward et al. ${ }^{3}$ found that in long-segment fusions using TLIF, there was a $5.6^{\circ}$ loss of lordosis at L4-5 and a loss of $2.4^{\circ}$ at L5S1. To further the conflicting data, Masuda et al. ${ }^{4}$ reported

ABBREVIATIONS ASD = adjacent-segment disease; $\mathrm{DA}=$ disc angle; $\mathrm{LL}$ = lumbar lordosis; $\mathrm{PGR}$ = posterior gap ratio; $\mathrm{PI}=$ pelvic incidence; $\mathrm{PI}-\mathrm{LL}=$ mismatch of $\mathrm{PI}$ and $\mathrm{LL} ; \mathrm{PT}$ = pelvic tilt; $\mathrm{SL}$ = segmental lordosis; $\mathrm{SS}$ = sacral slope; TLIF = transforaminal lumbar interbody fusion.

SUBMITTED September 13, 2020. ACCEPTED December 28, 2020.

INCLUDE WHEN CITING Published online July 9, 2021; DOI: 10.3171/2020.12.SPINE201665. 
no difference in postoperative LL change with TLIF or posterior fusion alone. In addition, Rothrock et al. ${ }^{5}$ performed a meta-analysis that showed that postoperative TLIF lordosis changes from $-3.71^{\circ}$ (kyphotic) to $18.8^{\circ}$ (lordotic). However, many of these reports have heterogeneous populations, heterogeneous surgical types, and various durations of follow-up. Given the conflicting reports of the extent of induction of lordosis or kyphosis by TLIF, we evaluated the factors that determine TLIF kyphosis or lordosis in patients who underwent single-level TLIF for low-grade spondylolisthesis without osteotomies and with a minimum 2-year follow-up.

\section{Methods}

\section{Patient Population}

Patients who underwent single-level, open TLIF for grade I or II degenerative spondylolisthesis (either with or without lysis) performed by 3 spine surgeons at the University of California, San Francisco, from 2006 to December 2016 with a minimum 2-year follow-up were retrospectively analyzed. IRB approval was obtained. Individual patient consent was not required in this study. Three-foot standing lateral radiographs were obtained preoperatively and at every follow-up. Radiographic analyses included measurements of overall LL, pelvic incidence (PI), sacral slope (SS), pelvic tilt (PT), mismatch of PI and LL (PILL), disc angle (DA) at the TLIF level, and SL. Preoperative and postoperative clinical and radiographic parameters, cage type, cage dimensions, and cage position in the interbody space were collected. Follow-up radiographic measurements were obtained at 2 years after index surgeries in patients who did not undergo revision. If there was revision surgery, the follow-up measurements were obtained prior to the revision. Patients with scoliosis $>10^{\circ}$, anterior or lateral surgery, non-TLIF surgery, minimally invasive TLIF, infection, tumor, osteoporosis, osteotomies at the TLIF level, or grade III or higher spondylolisthesis were all excluded.

\section{Surgical Technique}

The technique of open TLIF has been extensively described, but we will mention our technique here. Patients were positioned prone, and a midline approach was performed with dissection over the facets. Pedicle screw fixation was placed, and a total facetectomy was performed unilaterally to access Kambin's triangle. The disc space was entered, the endplates were prepared, and a trial was used to measure the disc space. The disc space was distracted to facilitate cage placement. Cages were titanium, expandable titanium, or polyetheretherketone (PEEK) filled with local autograft, iliac crest bone graft, allograft, or a combination. Rods were placed, gentle compression was applied, and set screws were locked. The wounds were closed in layers.

\section{Radiographic Assessment of TLIF}

Radiographic images obtained preoperatively, 1 month postoperatively, and at the last follow-up were assessed independently by two attending spine surgeons. The DA was defined as the angle between the supra- and subjacent end- plates of the TLIF. SL was calculated as the angle between the superior endplate of upper instrumented vertebra and the inferior endplate of the lower instrumented vertebra. Patient surgeries were categorized as either a "lordosing" TLIF ( $>0^{\circ}$ induction of lordosis) or a "kyphosing" TLIF ( $\leq 0^{\circ}$ induction of lordosis) based on postoperative SL - preoperative SL (Figs. 1 and 2). Cage position was calculated as the posterior gap ratio (PGR). The PGR is the ratio between the distance from the posterior margin of the inferior vertebral body to the posterior margin of the cage and the length of the anteroposterior diameter of the superior endplate of the inferior vertebra. ${ }^{6}$ Disc heights were measured as the averages of the distance between endplates at the posterior and anterior margins of the index level. Cage subsidence was determined by loss of postoperative disc height (grade $0,<25 \%$; grade I, $25 \%-$ $50 \%$; grade II, $>50 \%$; grade III, $50 \%-75 \%$; and grade IV, $>75 \%$ ) at last follow-up.

\section{Statistical Analysis}

Statistical analysis was performed using IBM SPSS version 20.0 (IBM Corp). Data were first categorized using descriptive statistics as means \pm standard deviations for continuous variables or as counts for categorical variables. Clinical and radiographic variables between the two groups were first compared using univariate analysis. Variables that had a $\mathrm{p}$ value of $<0.10$ were then entered into the multivariate logistic regression model. Correlation between continuous variables was performed using linear regression. Statistical analyses of intraobserver and interobserver reliability were performed. Statistical significance was defined at $\mathrm{p}<0.05$.

\section{Results}

A total of 137 patients met the inclusion criteria (male/ female ratio 51:86). The mean follow-up was 52.5 months (range 24-130 months). Twenty-nine patients had isthmic spondylolisthesis, and 108 patients had degenerative spondylolisthesis. One hundred one patients had Meyerding grade I spondylolisthesis, and 36 patients had grade II. Surgical levels included L3-4 in 10 patients, L4-5 in 95 patients, and L5-S1 in 32 patients. Static cages were used in 90 patients, and expandable cages were used in 47 patients. The mean cage lordosis was $6.5^{\circ} \pm 4.1^{\circ}$. The different lordoses were $0^{\circ}$ in 12 patients, $4^{\circ}$ in 9 patients, $5^{\circ}$ in 73 patients, $10^{\circ}$ in 11 patients, $12^{\circ}$ in 19 patients, and $15^{\circ}$ in 13 patients. The mean cage height was $11.2 \pm 2.4$ $\mathrm{mm}$ (range $7-17 \mathrm{~mm}$ ). Thirty-three patients underwent revision surgeries during the follow-up, with an overall revision rate of $24.1 \%$ (Table 1). Table 2 illustrates the various reasons for revision surgery.

\section{Overall Radiographic Parameters}

The overall mean preoperative DA, SL, and LL were lordotic at $4.69^{\circ} \pm 5.60^{\circ}, 19.15^{\circ} \pm 8.21^{\circ}$, and $52.5^{\circ} \pm 13.5^{\circ}$, respectively. At the 1-month follow-up, the mean lordosis of the DA, SL, and LL increased to $6.65^{\circ} \pm 4.60^{\circ}, 21.03^{\circ} \pm$ $6.98^{\circ}$, and $53.09^{\circ} \pm 12.22^{\circ}(\mathrm{p}=0.003, \mathrm{p}=0.038$, and $\mathrm{p}=$ 0.133 , respectively). The change in overall SL ranged from a loss of $13^{\circ}$ of lordosis to an increase of $17^{\circ}$ of lordosis. 


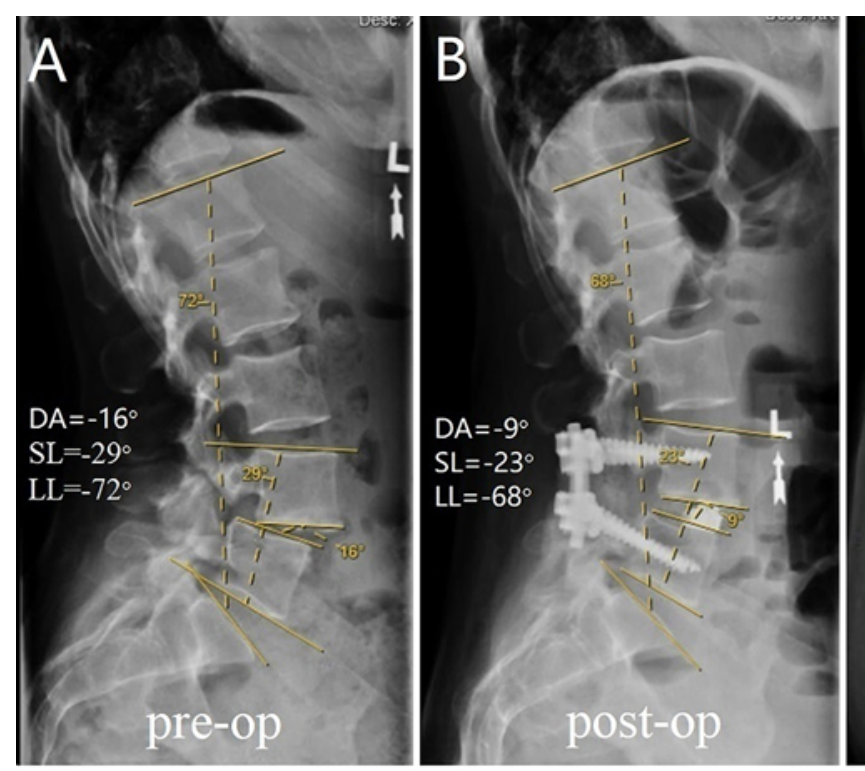

kyphosing TLIF
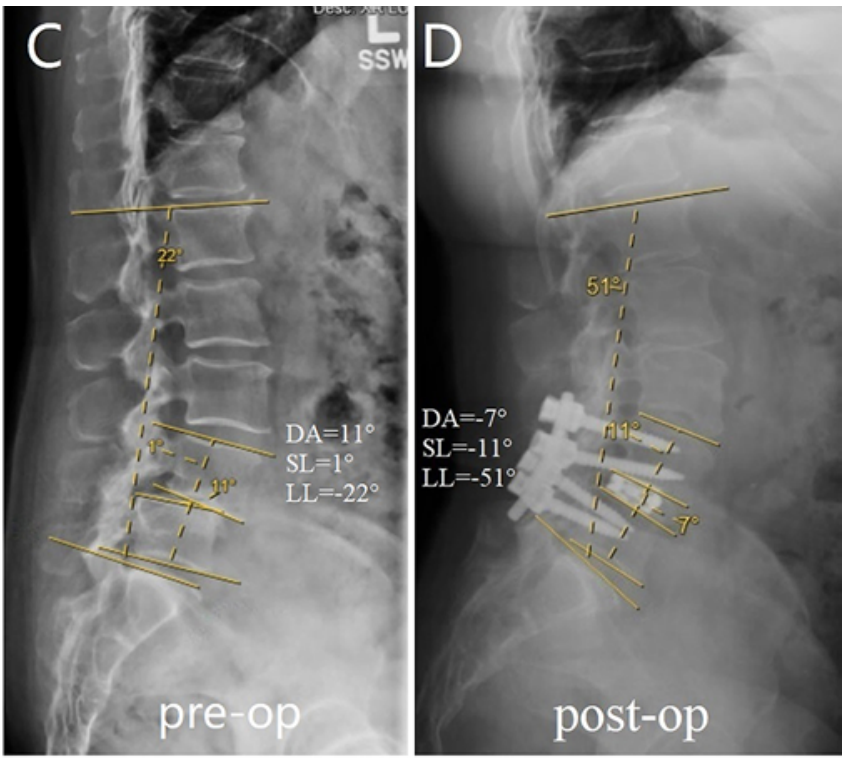

Lordosing TLIF

FIG. 1. A and B: Lateral radiographs obtained in a 65 -year-old man with $L 4-5$ grade II spondylolisthesis. The preoperative $D A, S L$, and LL were $-16^{\circ}$, $-29^{\circ}$, and $-72^{\circ}$, respectively, which decreased to $-9^{\circ},-23^{\circ}$, and $-68^{\circ}$ postoperatively. This patient had a kyphosing TLIF. C and D: Lateral radiographs obtained in a 58-year-old woman with L4-5 degenerative spondylolisthesis (grade II). The preoperative DA, SL, and LL were $11^{\circ}, 1^{\circ}$, and $-22^{\circ}$, which increased to $-7^{\circ},-11^{\circ}$, and $-51^{\circ}$. This patient had a lordosing TLIF. Figure is available in color online only.
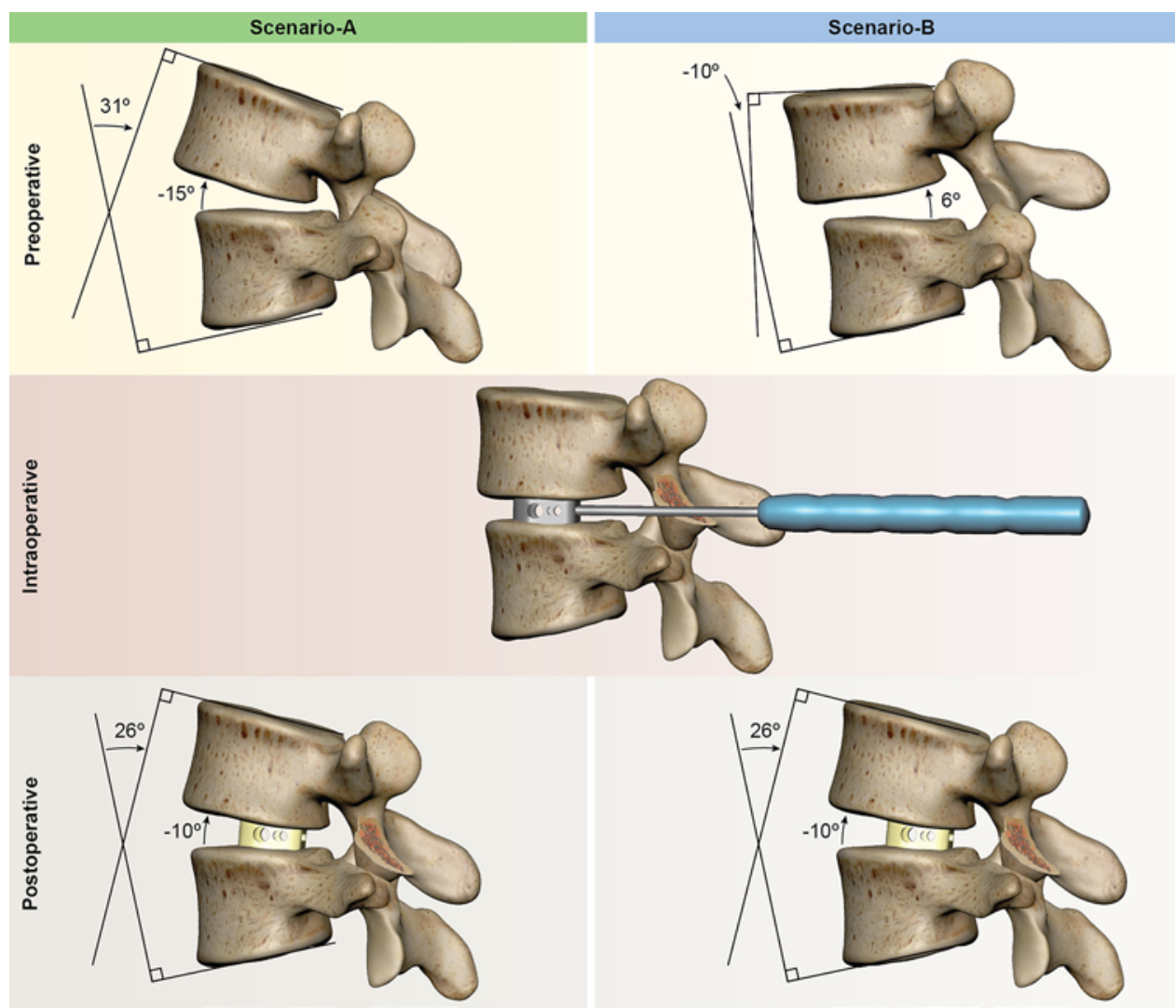

FIG. 2. Illustrations demonstrating the mechanism by which a TLIF can induce lordosis or kyphosis of the spine depending on the preoperative disc space angle. Scenario A: Kyphosing TLIF. The preoperative DA is $15^{\circ}$ lordotic, and the TLIF changes lordosis to match that of the TLIF cage. This results in a loss of $5^{\circ}$, kyphosing the spine. Scenario B: Lordosing TLIF. The preoperative DA is $6^{\circ}$ kyphotic, and the TLIF changes the lordosis to match that of the TLIF cage. This results in an increase of lordosis by $16^{\circ}$, lordosing the spine. This illustrates how the same TLIF can induce either kyphosis or lordosis based on the preoperative DA. Figure is available in color online only. 
Liu et al.

TABLE 1. Demographic characteristics of 137 patients treated by single-level TLIF

\begin{tabular}{|c|c|c|c|}
\hline & $\begin{array}{l}\text { Lordosing TLIF } \\
\qquad(n=79)\end{array}$ & $\begin{array}{l}\text { Kyphosing TLIF } \\
\quad(n=58)\end{array}$ & $\begin{array}{c}p \\
\text { Value }\end{array}$ \\
\hline Mean age, yrs & $58.2 \pm 12.3$ & $58.3 \pm 12.8$ & 0.946 \\
\hline M/F sex & $26 / 53$ & $25 / 33$ & 0.283 \\
\hline Mean BMI & $28.1 \pm 5.3$ & $29.2 \pm 7.7$ & 0.430 \\
\hline Level of fusion, no. & & & 0.082 \\
\hline L3-4 & 6 & 4 & \\
\hline L4-5 & 60 & 35 & \\
\hline L5-S1 & 13 & 19 & \\
\hline Isthmic/degenerative, no. & $12 / 67$ & $17 / 41$ & 0.057 \\
\hline Meyerding grade I/II, no. & $57 / 22$ & $44 / 14$ & 0.626 \\
\hline Mean disc height, mm & $4.8 \pm 2.5$ & $5.6 \pm 2.6$ & 0.161 \\
\hline Cage lordosis, $^{\circ}$ & $6.78 \pm 3.56$ & $6.44 \pm 4.37$ & 0.631 \\
\hline Cage position (PGR) & $24.2 \%$ & $18.8 \%$ & 0.023 \\
\hline Mean cage height, mm & $11.02 \pm 2.13$ & $11.49 \pm 2.86$ & 0.358 \\
\hline Cage type & & & 0.099 \\
\hline Expandable cage & 22 & 25 & \\
\hline Static cage & 57 & 33 & \\
\hline Mean follow-up, mos & $52.6 \pm 9.1$ & $52.4 \pm 9.5$ & 0.957 \\
\hline Pseudarthrosis & $8.9 \%(7 / 79)$ & $8.6 \%(5 / 58)$ & 0.999 \\
\hline Symptomatic ASD & $19.0 \%(15 / 79)$ & $8.6 \%(5 / 58)$ & 0.048 \\
\hline Reop & $29.1 \%(23 / 79)$ & $17.2 \%(10 / 58)$ & 0.071 \\
\hline
\end{tabular}

Mean values are presented as the mean \pm SD.

TABLE 2. Clinical characteristics of the 33 patients who underwent reoperation

\begin{tabular}{lccc}
\hline & $\begin{array}{c}\text { Pseudarthrosis } \\
(\mathrm{n}=12)\end{array}$ & $\begin{array}{c}\text { ASD } \\
(\mathrm{n}=19)\end{array}$ & $\begin{array}{c}\text { Other } \\
(\mathrm{n}=2)^{*}\end{array}$ \\
\hline Diagnosis & & & \\
\hline Isthmic & 6 & 3 & \\
\hline Degenerative & 6 & 16 & 2 \\
\hline Meyerding grade & & & \\
\hline I & 8 & 15 & 2 \\
\hline II & 4 & 4 & \\
\hline Surgical level & & & \\
\hline L3-4 & 0 & 3 & \\
\hline L4-5 & 6 & 13 & 1 \\
\hline L5-S1 & 6 & 3 & 1 \\
\hline Cage type & & & \\
\hline Expandable & 2 & 7 & \\
\hline Static & 10 & 12 & 2 \\
\hline Revision-free time, mos & & & \\
\hline$<12$ & 5 & 1 & 1 \\
\hline 12-24 & 4 & 3 & 1 \\
\hline$>24$ & 3 & 15 & \\
\hline
\end{tabular}

* Suspected pseudarthrosis in one case: fusion was found in surgical exploration. Wound infection in another case.
At the last follow-up (mean 52.5 months), DA, SL, and LL overall averages decreased to $4.70^{\circ} \pm 4.12^{\circ}, 18.41^{\circ} \pm 8.28^{\circ}$, and $52.55^{\circ} \pm 12.62^{\circ}$, which were not different from their preoperative values $(\mathrm{p}>0.05)$. The mean preoperative disc height was $5.1 \pm 2.5 \mathrm{~mm}$, increasing to $9.4 \pm 2.4 \mathrm{~mm}$ postoperatively and subsequently decreasing to $7.3 \pm 2.8$ $\mathrm{mm}$ at the last follow-up. Cage subsidence was observed in 52 patients ( 40 with grade I and 12 with grade II) at the last follow-up. Nine patients with grade II cage subsidence had expandable cages (9/47) while 3 patients had static cages $(3 / 90)(p=0.01)$. The mean preoperative PI, $\mathrm{PT}, \mathrm{SS}$, and sagittal vertical axis were $58.7^{\circ} \pm 11.9^{\circ}, 21.3^{\circ}$ $\pm 7.8^{\circ}$, and $37.6 \pm 9.0 \mathrm{~mm}$, respectively, and were not different immediately postoperatively or at the last follow-up $(p>0.05)$. An increase in SL by TLIF was not associated with cage type (static or expandable), magnitude of cage lordosis, cage height, or anatomical level of TLIF within the lumbar spine $(p>0.05)$; however, SL increased more in patients with more anterior cage placement and lower preoperative DAs (Fig. 3).

\section{Lordosing and Kyphosing TLIFs}

Seventy-nine patients had lordosing TLIFs, with an average SL increase of $5.72^{\circ} \pm 3.97^{\circ}$, and 58 patients had kyphosing TLIFs, with an average SL loss of $3.02^{\circ} \pm 2.98^{\circ}$. Overall LL increased by $3.6^{\circ} \pm 7.05^{\circ}$ in lordosing TLIFs and decreased by $1.2^{\circ} \pm 8.57^{\circ}$ in kyphosing TLIFs ( $\mathrm{p}=$ 0.012 ). Univariate and multivariate analyses showed that the preoperative DA and SL in lordosing TLIFs were significantly lower than the same measurements in kyphosing TLIFs (univariate $p<0.001$ and $p<0.001$, respectively; multivariate $\mathrm{p}=0.035$ and $\mathrm{p}<0.001$, respectively). The cage position was more anterior in lordosing TLIFs than kyphosing TLIFs (PGR: $24.2 \%$ vs $18.8 \%$; $\mathrm{p}=0.023$ ). Preoperative PI-LL was higher in lordosing TLIFs than in kyphosing TLIFs $\left(8.2^{\circ} \pm 10.7^{\circ}\right.$ vs $\left.4.3^{\circ} \pm 9.7^{\circ}, \mathrm{p}=0.032\right)$. There was no difference in age, sex, BMI, cage type, cage height, surgical levels, or spinopelvic parameters (PI, PT, $\mathrm{SS}$, and sagittal vertical axis) at the final follow-up between the two groups $(p>0.05)$. There was no difference in revision rates between kyphosing TLIFs and lordosing TLIFs $(\mathrm{p}=0.071)$. The revision rates due to adjacent-segment disease (ASD) were higher in lordosing TLIFs than in kyphosing TLIFs $(19.0 \%$ vs $8.6 \% ; p=0.048)$. The incidence of symptomatic pseudarthrosis was not different between kyphosing TLIFs and lordosing TLIFs $(\mathrm{p}>0.99)$ (Tables 1,3, and 4).

\section{Regression Analysis}

Linear regression analysis showed that the preoperative DA and preoperative SL were highly correlated with the change in SL after TLIF; these two parameters were most associated with whether a TLIF would cause kyphosis or lordosis at the spinal segment (Fig. 4). The regression equations were 1) change of $\mathrm{SL}=0.45 \times$ preoperative DA $+4.02\left(\mathrm{R}^{2}=0.198, \mathrm{p}<0.001\right)$ and 2$)$ change of $\mathrm{SL}=0.38$ $\times$ preoperative $\mathrm{SL}+9.2^{\circ}\left(\mathrm{R}^{2}=0.2931, \mathrm{p}<0.001\right)$.

\section{Discussion}

One common criticism of the TLIF is its poor ability 


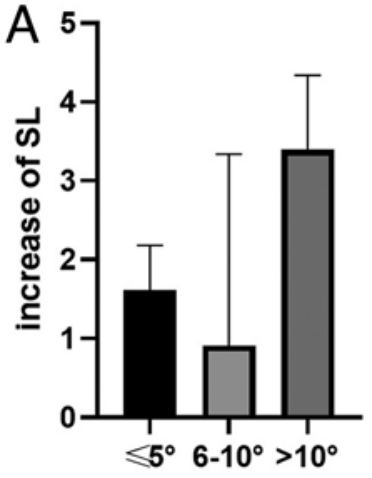

Lordosis of cage $p=0.288$

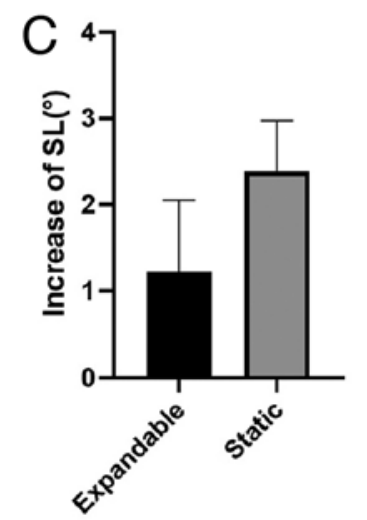

Cage types $p=0.251$

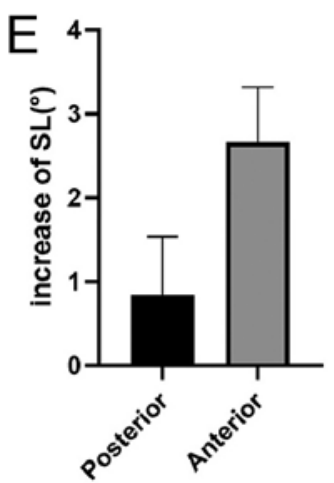

Position of Cage $p=0.031$

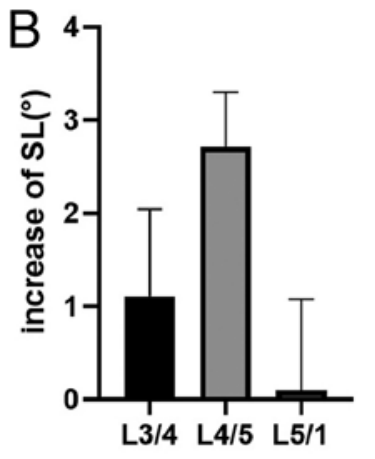

Operation levels $p=0.061$

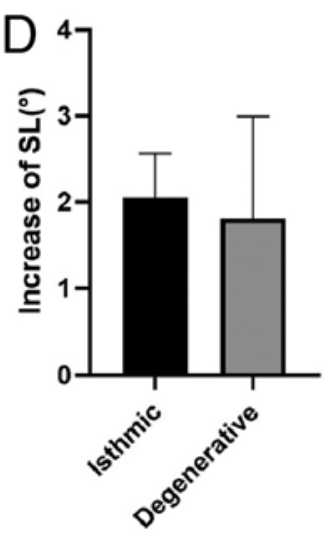

Spondylolysis $p=0.836$

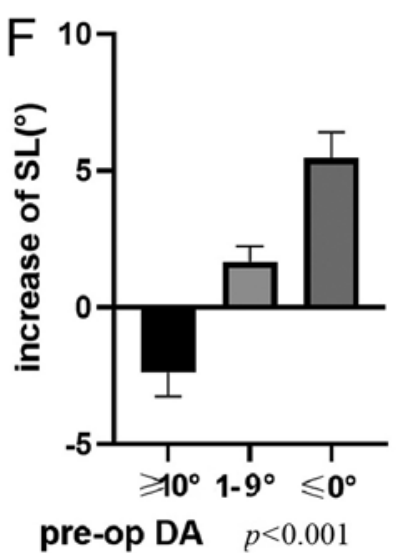

FIG. 3. The postoperative changes in SL were not different among groups with different cage lordosis $\left(\leq 5^{\circ}, 6^{\circ}-10^{\circ},>10^{\circ} ; \mathbf{A}\right)$, different TLIF levels (L3-4, L4-5, L5-S1; B), or different cage types (expandable vs static; C). There was no difference in SL change between patients with or without spondylolysis (D). SL increased more in patients with more anterior cage placement (E). SL decreased by $2.3^{\circ}$ in patients with preoperative $\mathrm{DA} \geq 10^{\circ}$, increased by $1.7^{\circ}$ in patients with a preoperative DA of $1^{\circ}-9^{\circ}$, and increased by $5.5^{\circ}$ in patients with a preoperative $\mathrm{DA} \leq$ $0^{\circ}(\mathbf{F})$. Bars represent the mean and error bars, SD.

to induce lordosis, with some surgeons calling TLIF a "kyphosing procedure." However, there are conflicting reports in the literature as to how much lordosis or kyphosis the TLIF actually produces. ${ }^{5}$ There are many reasons for such variations in LL induction, ranging from cage posi-

TABLE 3. Radiographic parameters in lordosing and kyphosing TLIFs

\begin{tabular}{cccr}
\hline & $\begin{array}{c}\text { Lordosing TLIF } \\
(\mathrm{n}=79)\end{array}$ & $\begin{array}{c}\text { Kyphosing TLIF } \\
(\mathrm{n}=58)\end{array}$ & \multicolumn{1}{c}{$\begin{array}{c}\mathrm{p} \\
\text { Value }\end{array}$} \\
\hline SL, $^{\circ}$ & & & \\
\hline Preop & $-15.83 \pm 7.17$ & $-23.38 \pm 7.47$ & $<0.001$ \\
\hline Postop & $-21.67 \pm 6.90$ & $-20.36 \pm 7.14$ & 0.282 \\
\hline Change & $5.72 \pm 3.97$ & $-3.02 \pm 2.98$ & $<0.001$ \\
\hline Follow-up & $-18.14 \pm 9.06$ & $-17.95 \pm 9.53$ & 0.905 \\
\hline Disc angle, ${ }^{\circ}$ & & & \\
\hline Preop & $-2.79 \pm 4.88$ & $-7.33 \pm 5.47$ & $<0.001$ \\
\hline Postop & $-7.23 \pm 4.39$ & $-5.83 \pm 4.76$ & 0.080 \\
\hline Change & $4.35 \pm 4.01$ & $-1.5 \pm 4.65$ & $<0.001$ \\
\hline Follow-up & $-5.07 \pm 4.37$ & $-4.21 \pm 3.70$ & 0.229 \\
\hline LL, ${ }^{\circ}$ & & & \\
\hline Preop & $-50.3 \pm 13.95$ & $-54.90 \pm 13.03$ & 0.061 \\
\hline Postop & $-54.9 \pm 12.94$ & $-53.7 \pm 12.41$ & 0.870 \\
\hline Change & $3.6 \pm 7.05$ & $-1.2 \pm 8.57$ & 0.012 \\
\hline Follow-up & $52.00 \pm 14.29$ & $51.13 \pm 13.22$ & 0.443 \\
\hline
\end{tabular}

tion to compression of the pedicle screws with or without osteotomies to the use of smaller cages that act as pivot points. Although many of these concepts make intuitive sense, the data to confirm that these notions are sparse, especially in the modern era of significant variation in cage types, cage material, TLIF techniques, and surgical goals of lordosis induction.

Historically, there have been conflicting reports of the effect on LL by TLIF. Isaacs et al. ${ }^{7}$ showed an increase in the TLIF DA of $1.0^{\circ}$ and an increase in LL of $1.4^{\circ}$ at the 3-month follow-up. Hawasli et al. ${ }^{8}$ showed a $2.3^{\circ} \mathrm{SL}$ increase with static cage TLIFs and a $5.2^{\circ}$ increase in SL with expandable cage TLIFs. However, their follow-up was extremely short (as low as 0.9 months). Such short follow-up would not have accounted for settling or subsidence. On the other hand, Dorward et al. ${ }^{3}$ reported a loss of lordosis of $1.7^{\circ}$ at L4-5 and $1.5^{\circ}$ at L5-S1 after TLIF with a minimum 2-year follow-up. Jagannathan et al. reported improved lordosis after TLIF. ${ }^{1}$ However, their technique included bilateral total facetectomies with compression of the segment, representing a unique subset of TLIF surgery. ${ }^{9}$ In our study, this subset of patients was excluded because of the effect of bilateral facetectomies on lordosis.

Other studies have specifically evaluated which factors were associated with TLIF lordosis. Kwon et al..$^{10}$ showed that the more anteriorly the TLIF cage was placed, the more lordosis was induced. Our study showed a similar finding: lordosing TLIFs had more anterior placement of interbody cages than kyphosing TLIFs. Vaishnav et al. ${ }^{11}$ reported that in patients with low preoperative LL, there was an increase in lordosis regardless of whether a static or expandable cage was used; however, in patients with high LL, only expandable cages preserved lordosis while static cages induced kyphosis. Their results are consistent with our findings that preoperative lordosis was highly predictive of the change after TLIF. However, they only 
TABLE 4. Multivariate regression analysis of predictors of postoperative segmental lordosis

\begin{tabular}{lrrrrr}
\hline & B & SE & Beta & t Value & p Value \\
\hline Cage lordosis & 0.122 & 0.137 & 0.088 & 0.892 & 0.374 \\
\hline Cage position & -1.795 & 0.844 & -0.157 & -2.127 & $\mathbf{0 . 0 3 5}$ \\
\hline Cage type & 1.412 & 1.166 & 0.119 & 1.211 & 0.228 \\
\hline Spondylolysis & -0.902 & 1.070 & -0.065 & -0.843 & 0.401 \\
\hline Surgical level & -0.188 & 0.887 & -0.017 & -0.212 & 0.832 \\
\hline Preop DA & 0.192 & 0.092 & 0.187 & 2.079 & $\mathbf{0 . 0 4 0}$ \\
\hline Preop SL & 0.314 & 0.068 & 0.433 & 4.641 & $<0.001$ \\
\hline
\end{tabular}

Dependent variables: postoperative change in segmental lordosis (adjusted $R^{2}$ $=0.345, p<0.001)$; cage type ( 0 , static cage; 1 , expandable cage); surgical levels (0, L3-4; 1, L4-5; 2, L5-S1). Boldface type indicates statistical significance.

performed postoperative measurements within 2 weeks after surgery. In our study, we have a minimum 2-year follow-up, and we did not observe a difference with expandable cages. One reason for this difference is the loss of correction from settling and subsidence of the expandable cages with the longer follow-up in our study, a clinical condition that may not be observed immediately after surgery or at the 2-week mark, as in their study. Moreover, Park et al. ${ }^{12}$ showed that the biggest predictor of surgical alleviation of foraminal stenosis with interbody fusion is the change in the disc height, not the absolute cage size or absolute post-TLIF disc space height itself. This is consistent with the notion that the change in lordosis - not absolute post-TLIF lordosis - is a main factor in whether or not a TLIF causes lordosis or kyphosis of the spine. In a highly lordotic spine, the change will be either minimal or even negative because the spinal segment is already near maximum lordosis, but in a nonlordotic or kyphotic spine, a TLIF will result in lordosis induction because there is a change from a nonlordotic angle to a lordotic or neutral angle.

In our study, we found that in highly preoperative lordotic segments, the TLIF will induce kyphosis, and in less-lordotic segments, the TLIF will induce lordosis. Also, we found that anterior cage position is associated with increased lordosis, similar to the findings of Kwon et al. ${ }^{9}$ This makes sense on two fronts. First, the corridor through Kambin's triangle is of limited size. This precludes placement of extremely lordotic cages through this triangle. Moreover, with expandable cages that may match such lordosis, subsidence or settling may result in loss of lordosis over time, an observation that we saw with a longer follow-up compared with other studies with shorter follow-up times. Second, in spines that are highly lordotic preoperatively, the TLIF itself will reduce that lordosis to match the cage lordosis, which may not be as lordotic as the preexisting spinal segment. Conversely, in nonlordotic or even kyphotic spines, the TLIF will change the spinal segment to match the inherently lordotic TLIF cage, which may be more lordotic than the preexisting spinal segment. Kepler et al. ${ }^{13}$ had similar findings with lateral lumbar interbody fusion, showing that lordosis increase
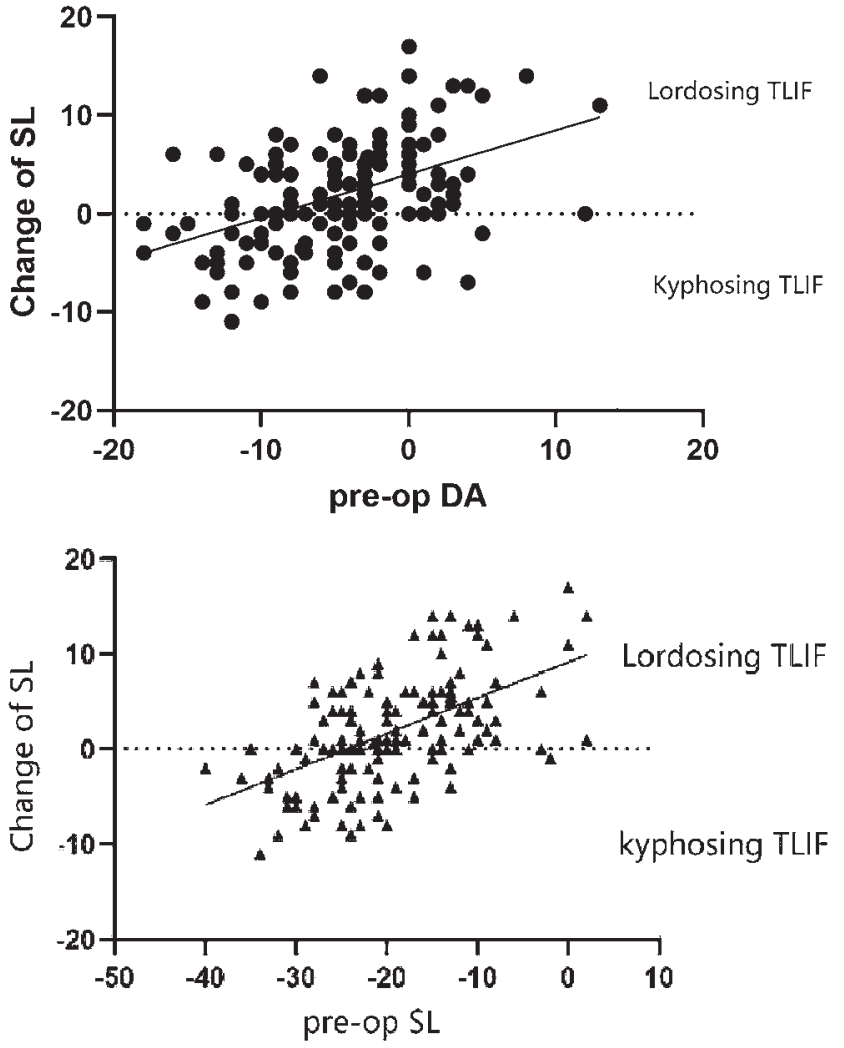

FIG. 4. Scatterplot demonstrating the preoperative DA (upper) and preoperative SL (lower) were correlated with change in postoperative SL.

was inversely associated with preoperative lordosis. Our data were consistent with the notion that preoperative angulation was the most significant factor of the change in lordosis after TLIF, observed both on univariate and multivariate analyses.

The findings in our study may partially explain why the literature has conflicting data about the lordosing or kyphosing nature of TLIF. Many studies may not take into account preoperative lordosis, cage position, or long-term subsidence associated with expandable cages. Thus, their immediate postoperative lordosis may not be the same as their long-term lordosis. Moreover, TLIFs may induce kyphosis of segments that are highly lordotic, and they may induce lordosis of nonlordotic segments, resulting in different radiographic results in different studies. ${ }^{14}$ In addition, if the study does not take into account cage position or settling, another result may be observed. With regard to specifics in our study, we excluded osteotomy patients, and this included bilateral facetectomy patients. There are times when surgeons will perform bilateral facetectomies in order to more fully release the disc space. However, because such bilateral facetectomies can also affect lordosis, we excluded all these patients from this study to eliminate this factor as a confounding variable. Also, our study included only open surgeries, and specific studies with regard to minimally invasive TLIF would be interesting to identify if similar results are observed.

Our revision surgery rates of $29.1 \%$ in lordosing TLIFs 
and $17.2 \%$ in kyphosing TLIFs $(\mathrm{p}=0.071)$ are generally higher than those in published reports..$^{16-18}$ However, one reason for these high rates is related to the very long follow-up ( $>10$ years in some) compared with other studies. Although the minimum follow-up time was 2 years, there were patients who had much longer follow-up. We chose to include these patients with longer follow-up to try and capture long-term sequelae, such ASD. With such long follow-up, patients captured in this cohort may have revisions unrelated to their index surgery but related to ASD. We found that the rate of symptomatic ASD was higher in lordosing TLIFs than in kyhposing TLIFs. However, lordosing TLIFs also had more preoperative PI-LL mismatch, consistent with previous reports showing that PILL mismatch is associated with ASD..$^{15}$

There are limitations to this study. First, this is a singlecenter study, and multicenter studies may be more ideal. Multicenter studies may account for surgeon and institutional variability, patient population variability, and regional variations in practice patterns. However, we did include data from 3 spine surgeons-both orthopedic and neurosurgery-to include somewhat of a varied patient population. Second, this is a retrospective study, and thus selection biases may have been introduced with regard to lordosis induction during surgery. This should be taken into consideration when interpreting the data. Third, it should be considered that many of these TLIFs were performed without the direct goal of lordosis induction but rather the goal of decompression, stabilization, and possible reduction of spondylolisthesis. Although the primary goal of these TLIFs was not lordosis induction, this data set may represent real-world scenarios in which surgeons perform TLIFs for the other three aforementioned reasons. However, the strengths of this study are the long-term follow-up, pre- and postoperative radiographic analyses, and assessment of other possible confounders accounting for lordosis.

\section{Conclusions}

Whether a TLIF induces kyphosis or lordosis is highly dependent on the preoperative DA, SL, and cage position. Less-lordotic segments became more lordotic postoperatively, and highly lordotic segments may lose lordosis after TLIF. Anterior cage placement resulted in more lordosis. The preoperative lordosis of the spinal segment intraoperative cage placement may portend the change in lordosis by TLIF.

\section{References}

1. Jagannathan J, Sansur CA, Oskouian RJ Jr, et al. Radiographic restoration of lumbar alignment after transforaminal lumbar interbody fusion. Neurosurgery. 2009;64(5):955-964.

2. Hsieh PC, Koski TR, O'Shaughnessy BA, et al. Anterior lumbar interbody fusion in comparison with transforaminal lumbar interbody fusion: implications for the restoration of foraminal height, local disc angle, lumbar lordosis, and sagittal balance. J Neurosurg Spine. 2007;7(4):379-386.

3. Dorward IG, Lenke LG, Bridwell KH, et al. Transforaminal versus anterior lumbar interbody fusion in long deformity constructs: a matched cohort analysis. Spine (Phila Pa 1976). 2013;38(12):E755-E762.
4. Masuda K, Higashi T, Yamada K, et al. The surgical outcome of decompression alone versus decompression with limited fusion for degenerative lumbar scoliosis. J Neurosurg Spine. 2018;29(3):259-264.

5. Rothrock RJ, McNeill IT, Yaeger K, et al. Lumbar lordosis correction with interbody fusion: systematic literature review and analysis. World Neurosurg. 2018;118:21-31.

6. Landham PR, Don AS, Robertson PA. Do position and size matter? An analysis of cage and placement variables for optimum lordosis in PLIF reconstruction. Eur Spine J. 2017; 26(11):2843-2850.

7. Isaacs RE, Sembrano JN, Tohmeh AG. Two-year comparative outcomes of MIS lateral and MIS transforaminal interbody fusion in the treatment of degenerative spondylolisthesis: part II: radiographic findings. Spine (Phila Pa 1976). 2016; 41(suppl 8):S133-S144.

8. Hawasli AH, Khalifeh JM, Chatrath A, et al. Minimally invasive transforaminal lumbar interbody fusion with expandable versus static interbody devices: radiographic assessment of sagittal segmental and pelvic parameters. Neurosurg Focus. 2017;43(2):E10.

9. Duan PG, Mehra RN, Wang M, Chou D. Posterior column osteotomy of the lumbar spine: 2-dimensional operative video. Oper Neurosurg (Hagerstown). 2020;19(4):E395.

10. Kwon BK, Berta S, Daffner SD, et al. Radiographic analysis of transforaminal lumbar interbody fusion for the treatment of adult isthmic spondylolisthesis. J Spinal Disord Tech. 2003;16(5):469-476.

11. Vaishnav AS, Saville P, McAnany S, et al. Retrospective review of immediate restoration of lordosis in single-level minimally invasive transforaminal lumbar interbody fusion: a comparison of static and expandable interbody cages. Oper Neurosurg (Hagerstown). 2020;18(5):518-523.

12. Park D, Mummaneni PV, Mehra R, et al. Predictors of the need for laminectomy after indirect decompression via initial anterior or lateral lumbar interbody fusion. J Neurosurg Spine. 2020;32(6):781-787.

13. Kepler CK, Huang RC, Sharma AK, et al. Factors influencing segmental lumbar lordosis after lateral transpsoas interbody fusion. Orthop Surg. 2012;4(2):71-75.

14. Zhu C, Qiu X, Zhuang M, et al. Surgical outcomes of singlelevel transforaminal lumbar interbody fusion for degenerative spondylolisthesis with and without kyphotic alignment. World Neurosurg. 2018;117:e396-e402.

15. Tempel ZJ, Gandhoke GS, Bolinger BD, et al. The influence of pelvic incidence and lumbar lordosis mismatch on development of symptomatic adjacent level disease following single-level transforaminal lumbar interbody fusion. Neurosurgery. 2017;80(6):880-886.

16. Jin-Tao Q, Yu T, Mei W, et al. Comparison of MIS vs. open PLIF/TLIF with regard to clinical improvement, fusion rate, and incidence of major complication: a meta-analysis. Eur Spine J. 2015;24(5):1058-1065.

17. Chan AK, Bisson EF, Bydon M, et al. A comparison of minimally invasive and open transforaminal lumbar interbody fusion for grade 1 degenerative lumbar spondylolisthesis: an analysis of the prospective Quality Outcomes Database. Neurosurgery. 2020;87(3):555-562.

18. Buyuk AF, Shafa E, Dawson JM, Schwender JD. Complications with minimally invasive transforaminal lumbar interbody fusion for degenerative spondylolisthesis in the obese population. Spine (Phila Pa 1976). 2019;44(23):E1401E1408.

\section{Disclosures}

Dr. Mummaneni: consultant for DePuy Synthes, Globus, and Stryker; direct stock ownership in Spinicity/ISD; royalties from DePuy Synthes, Thieme Publishing, and Springer Publishing; 
Liu et al.

support of non-study-related clinical or research effort from AO Spine, NREF, and ISSG. Dr. Berven: ownership in Green Sun Medical; royalties from Stryker; and consultant for Medtronic, Innvasis, Globus, Stryker, and Integrity. Dr. Chou: consultant for and royalties from Globus.

\section{Author Contributions}

Conception and design: Liu, Li, Chou. Acquisition of data: Liu, Duan, Xie. Analysis and interpretation of data: Liu. Drafting the article: Liu. Critically revising the article: Berven, Chou. Reviewed submitted version of manuscript: Liu, Mummaneni, $\mathrm{Xie}, \mathrm{Li}, \mathrm{Chou}$. Approved the final version of the manuscript on behalf of all authors: Liu. Statistical analysis: Dong. Administrative/technical/material support: Mummaneni, Berven. Study supervision: Chou.

\section{Correspondence}

Jinping Liu: Sichuan Academy of Medical Sciences and Sichuan Provincial People's Hospital, School of Medicine, University of Electronic Science and Technology of China, Chengdu, Sichuan, China. liujinpingsw@med.uestc.edu.cn. 